\title{
EFEITO DO EXTRATO AQUOSO DE DIFERENTES ESPÉCIES DE BOLDO SOBRE A GERMINAÇÃO E INDICE MITÓTICO DE ALLIU M CEPA L.
}

\author{
J.R.V. Iganci, V .L. Bobrowski, G . H eiden, V.C. Stein, B.H .G. Rocha \\ Universidade Federal de Pelotas, Instituto de Biologia, Departamento de Zoologia e Genética, CP 354, CEP \\ 96010-970, Pelotas, RS, Brasil. E-mail: vera.bobrowski@ufpel.tche.br
}

RESUMO

A gentes químicos produzidos em al gumas plantas podem provocar alterações no desenvolvimento de outras plantas ou até mesmo de outros organismos. Ensaios laboratoriais podem demonstrar os resultados destasinterações, porém, sem considerar a ação do ambiente. Com este trabalho objetivou-seidentificar ainfluênciadeextratosvegetais de3espéciesconhecidasno Brasil popularmente como boldo sobre o desenvolvimento de Allium cepa. Os bioensaios foram conduzidos em germinador a $25^{\circ} \mathrm{C}$, com extrato aquoso obtido por infusão de fol has frescas na concentração de $30{\mathrm{~g} . \mathrm{L}^{-1}}^{-1}$ a água destilada como controle. Os testes de primeira contagem e germi nação, queaval iam efeito al el opáti co foram realizados com 4 repetições de 50 sementes. Para determinação da citotoxicidade, através do índice mitótico (IM) foram contadas pela técnica de varredura 2.400 célul as por extrato. Os bioensai os realizados revel aram que os extratos vegetais interferiram sobrea germinação e sobrea divisão celular em célul as meristemáticas radiculares de A. cepa. Sementes expostas ao extrato de Vernonia condensata apresentaram as maiores divergências em relação ao grupo controle.

PALAVRAS-CHAVE: Divisão celular, alel opatia,V ernonia condensata, Plectrantus barbatus, Plectrantus amboinicus.

\begin{abstract}
EFFECT OF AQUOUSEXTRACTSOFTHE "BOLDO"SPECIESON THE GERMINATION AND MITOTIC INDEX OF A LLIU M CEPA L. Chemical agents produced by some plants may cause changes on the development of other plants and organisms. Laboratory assays can show the results of theseinteractions, however, without considering theenvironmental action. Theaimof this work was to identify theinfluence of plant extracts from 3 species of plantsusually known in Brazil as "boldo" on the development of Allium cepa seeds. Bioassay were carried out in a germinator at $25^{\circ} \mathrm{C}$ with aqueous extract obtained by infusion of thefresh leavesin concentration of $30 \mathrm{~g} . \mathrm{L}^{-1}$ and distilled water asa control. The first score and germination tests that evaluated allel opathic effect were done with 4 repetitions of 50 seeds/ extract. For thecytotoxicity assay, using mitoticindex (MI), 2,400 cells/ extractwerescored throughthescan technique. Thebioassay reveal ed that the plant extracts act on the A . cepa germination and root-tip cell division. Seeds exposed to V ernonia condensata extract showed thehighest divergencewhen compared with the control group.
\end{abstract}

KEY WORDS: Cell division, al lelopathy,V ernonia condensata, Plectrantusbarbatus,Plectrantusamboinicus.

\section{INTRODUÇÃO}

A lgumas plantas produzem compostos do metabolismo secundário que atuam inibindo ou favorecendooprocessogerminativo bemcomooprocesso de divisãocelular. Estescompostossão conhecidoscomo al el opáticos. O termo alelopatia refere-seà capacidadequeasplantastêm deinterferir no desenvolvimento de outras plantas, por meio de substâncias que liberam na atmosfera ou, quase sempre, no solo (Medeiros, 1990; Ferreira \& Borghetti, 2004). A ação al elopática se dá através do efeito destas substâncias al iado àscondiçõesambientais. A al elopatia podeser um fator determinante do sucesso ou insucesso no cultivo de plantas (FERREIRA \& BorghetTI, 2004).

O uso de ensaios biológicos para avaliação da bioatividade de extratos, frações e compostos isolados deplantas tem sido freqüentementeincorporado a identificação e monitoramento de substâncias potencialmente tóxicas (N oLdin et al., 2003).

A ação visível dosaleloquími cos sobreas plantas ésomenteuma sinal ização secundária demudanças 
anteriores. Assim, os estudos referentes ao efeito de aleloquímicos sobre a germinação e/ ou desenvolvimento da planta são manifestações secundárias de processos ocorridos a nível molecular ecelular inicialmente(FERREIRA \&A QUILA, 2000; FERREIRA \& BORGHETTI, 2004). A maioria dos estudos em al el opatia refere-se apenas ao efeito do al el oquímico sobrea germinação e o crescimento da planta-teste, sem considerar os eventos cel ulares relacionados às mudanças fisi ológicas (PIREs et al., 2001) e genéticas.

Compostos químicos que muitas vezes apresentam efeito alelopático são também utilizados na medicina popular na cura de doenças, onde a preparação e uso adequado trazem benefícios, porém seus efeitos genotóxicos e mutagênicos necessitam de melhores investigações (N UnES \& ARAújo, 2003).

Muitas pessoas acreditam erroneamentequecultivam boldo-do-chile Peumus boldus), porém, essa planta é muito rara no Brasil. Outras plantas são também conhecidas como boldo, principalmente, o boldo-da-terra (Plectrantus barbatus - Lamiaceae), o boldo-miúdo (Plectrantus amboinicus - Lamiaceae) eo boldo-baiano (V ernonia condensata - Asteraceae), que apresentam diferentes efeitos col aterais eindicações, apesar de serem utilizados como a mesma planta em diferentes regiões (BLANCO, 2005).

Os princípios ativos constituintes divergem entre estas espécies como, por exemplo, o boldo miúdo apresenta como principais o timol, o carvacrol e o cariofileno, enquanto que o boldo baiano apresenta ácidoclorogênico, saponinas, glicosídeo cardiotônico (vernonina), lactonas sesquiterpênicas, flavonóidese oboldo-da-terraéricoemguaienoefenchona, terpenos (barbatusina, ciclobarbatusina, cariocal), triterpenóides eesteróides (CIAGRI, 2005).

Com estetrabal ho objetivou-se avaliar o efeito do extrato aquoso de 3 diferentes espécimes conhecidos popularmente como boldo sobre o desenvol vimento inicial e índice mitótico de células meristemáticas radiculares de cebola, com o intuito de identificar a existênciadeefeito al el opático destes extratossobreo desenvolvimento deA llium cepa (cebola).

\section{MATERIAISE MÉTODOS}

Folhas frescas de $\mathrm{P}$. barbatus, P. amboinicus e V. condensata foram coletadas para o preparo do extrato aquoso através deinfusão, ondeforamutilizadas $30 \mathrm{~g}$ defolhaspor litrodeáguadestiladaparacadaumdos extratos.

As sementes de cebola foram pré-embebidas durante 48h em gerbox contendo papel germitesteumedecido com água destilada e mantidos a $25 \pm 10$ C. A pós, as sementes foram transferidas para gerboxes contendo papel embebido nos diferentes extratos, exceto a amostra controle, que permaneceu em água destilada.

A primeira contagem foi realizada aos seis dias e o teste de germinabilidade aos 12 (BRASIL, 1992). Foram consideradas germinadas as sementes queapresentaram radícula com no mínimo $50 \%$ do tamanho dasemente(FERREIRA \&Á QUILA, 2000). A porcentagem de germinação na primeira contagem e germinabilidade (G) foi calculada com o uso da seguintefórmula:

$$
\mathrm{G}=(\mathrm{N} / \mathrm{A}) \times 100
$$

sendo que $\mathrm{N}$ =número total desementesgerminadas; $\mathrm{A}=$ número total de sementes colocadas para germinar.

Paraanálisedoíndicemitótico, asradículasforam coletadas aos seis dias após o teste de primeira contagem e preparadas através da técnica de esmagamento (Guerra \& SOUzA, 2002), fixadas em Carnoy (3:1, etanol: ácido acético glacial) por duas horas, hidrolisadas em $\mathrm{HCl} 5 \mathrm{~N}$ durantequinzeminutosem temperatura ambiente, lavadas em água destilada e coradas com orceína acética 5\%. As células foram analisadas por varredura, em microscópio ótico com aumento de 400X sendo analisadas 2.400 células para cada um dos tratamentos, observando-se o número de células em cada fase da mitose. $O$ índice mitótico (IM) foi obtido através da seguinte equação (PIREs et al., 2001):

$$
\mathrm{IM}=(\mathrm{m} / \mathrm{T}) \times 100
$$

sendo que $\mathrm{m}=$ número de células em mitose; $\mathrm{T}=$ número total de células.

Para análise de germinação o delineamento experimental utilizadofoi intei ramentecasual izado, com4 repetições onde cada repetição era composta por quatro amostras com 50 sementes ea análise da variação pelo pacote estatístico Sanest. A comparação das mé dias foi realizada através do teste de Duncan com $5 \%$ de probabilidade (BEIGUELMAN, 2002). Para comparação demédias doíndicemitótico os tratamentosforam comparados pelo teste de qui-quadrado.

\section{RESULTADOSE DISCUSSÃO}

N a primei ra avaliação aos seis dias o grupo controleapresentou $47 \%$ degerminação enquanto queo tratamento com $\mathrm{P}$. barbatus apresentou $61 \%$, com $\mathrm{P}$. amboinicus $46 \%$ e com $V$. condensata $65 \%$ degerminação, as diferenças observadas entre os tratamentos não foram estatisticamente significativas. 
No entanto no testedegerminação podemos verificar queentreos resultados obtidos houvediferença significativa $(p<0,05)$, onde o tratamento controle apresentou $66 \%$ degerminação, o tratamento com $P$. barbatus apresentou $71 \%$, comP. amboinicus $55 \%$ ecom V. condensata $76 \%$ de germinação (Fig. 1). Através deste teste podemos observar que o extrato de $\mathrm{P}$. amboi nicus causou um retardo nagerminação decebo$\mathrm{la}$, enquanto queo extrato deV . condensata causou uma aceleração no processo quando comparados com o controle.

Estes resultados diferem da citação de FerReIRA \& BORGHETTI (2004) onde os autores citam que muitas vezeso efeitoalelopáticonãoésobreagerminabilidade (percentual final degerminação no tempo), massobre a velocidade de germinação ou outro parâmetro do processo. Como podemosobservar paraestesextratos o teste de primeira contagem não demonstrou ser afetado pelos compostos das plantas, maso seu efeito foi detectado sobre a germinação final não só retardando o processo como descreve LABOURIAU (1983), mas também o ativando. Estes resultados estão de acordo CHON et al. (2005) quedescreveal elopatiacomo interaçõesquímicasentreplantastantoestimulatórias quanto inibitórias.

KATHIRESAN (2000) observou redução no desenvolvimento de plantas aquáticas com o uso de pó deC. amboinicus em concentração a partir de $10 \mathrm{~g} \cdot \mathrm{L}^{-1}$, atribuindo aosprincípiosativosalfa-humuleno, carvacrol, timol, alfa-pineno e alfa-terpino o efeito tóxico da planta, resultado similar ao observado na figura 1 com concentração de 30 g.L.-1 .

Segundo FerREIRA \& ÁquILA (2000), a germinação émenossensível aosaleloquímicosqueocrescimento da plântula, porém, a quantificação experimental é muitomaissimples, poisparacadasementeofenômeno édiscreto, germina ou não germina. N essecontexto, podemosverificar queassementes decebolaforam sensíveis ao extrato de duas espécies de plantas co-

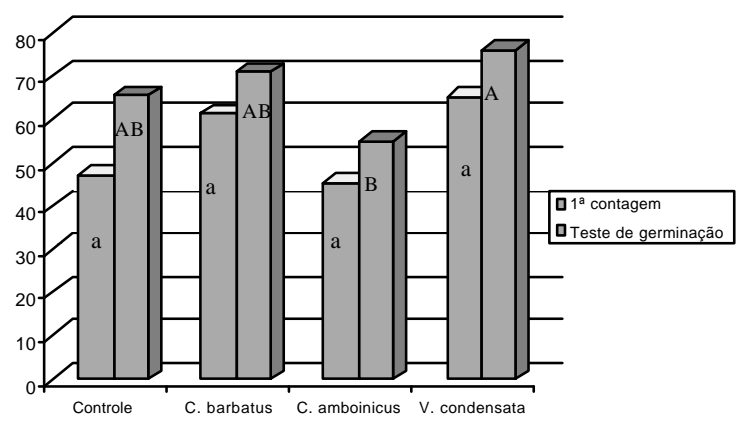

Fig. 1- A val iação do percentual desementes germinadas nostestedeprimeiracontagemegerminabilidade. Letras distintas entre médias do mesmo testeindicam que estas diferementresi a5\% deprobabilidaepelotestedeDuncan. nhecidas popularmente como boldo, sofrendo efeito alelopático.

Deacordo Carvalho et al . (1996) estudoscomoeste sobre substâncias al el opáticos e a identificação das plantas que possuem princípios ativos capazes de causar al gum efeitoéassunto degrandeimportância, tanto nautilização deextratos capazes deinibir plantas daninhas na tentativa de diminuir o uso de herbicidas comerciais, quando na determinação de práticas culturais e de manejos mais adequados que evitem a interferência destas substâncias no crescimento de outras (GATTı et al., 2004).

Outro efeito causado por substânciasal elopáticas é o aparecimento de plântulas anormais, sendo a necrose da radícula um dos sintomas mais comuns (FerReIRA \& Áquila, 2000). Compostos químicos que muitas vezes apresentam efeito al elopático também podem ter efeitos genotóxicos e mutagênicos (N UNES \& Araújo, 2003). Os extratos testados neste experimento produziram efeito sobreo processo de divisão celular da cebola, mas não foram detectados efeitos citotóxico ou genotóxico esim um aumento no índice de divisão celular significativo quando comparado ao controle.

O índicemitótico observado foi de $29,20 \%$ para as radículas tratadas com $P$. barbatus, 20,95\% para aquelas tratadas com P. amboinicus, 39,83\% para as tratadas com $V$. condensata e 5,2\% na amostra controle, como são mostrados na Figura 2.

Segundo Rodrigues et al. (1992), os compostos alelopáticos são inibidores de germinação e crescimento, pois interferem na divisão celular, permeabilidade de membranas e na ativação de enzimas, porém os efeitos observados nestetrabal ho parecem indicar quenão só a inibição, mas tambéma aceleração pode interferir no processo de divisão celular, pois o aumento no índice de divisão parece corroborar os dados de germinabilidade das sementes de cebola.

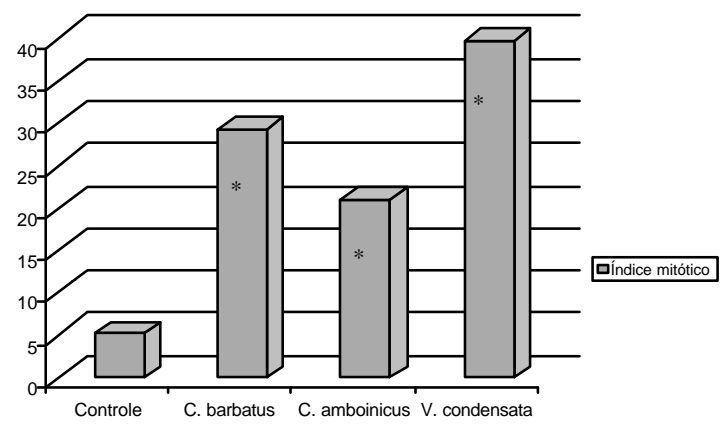

Fig. 2 - Índice de divisão mitótica das células de cebola tratadas com extratos de espécies conhecidas popularmentecomo boldo. Médiascom*diferemestatisticamente do controle pelo teste de $\chi^{2}<0,01$. 
O índicededivisão mitóticaapresentou diferença entreostratamentos, oquepodeindicar uma distinta ação fisiológica decada um dos extratos aplicados à cebola. Segundo FerReIRA \& BorghetTI (2004), a emergência da plântula e o seu crescimento são as fases mais sensíveis na ontogênese do indivíduo.

Algumas célulastratadas com extrato deP . barbatus apresentaram anomalias nucleares do tipo aneugênese durante a divisão mitótica, porém, os dados não foram avaliados estatisticamente. A interferência na divisão celular causada pela ação do extrato com efeitosobreo desenvolvimento dosistema radicular provavel menterepresenta umdosmecanismos de ação do extrato sobre o desenvol vimento da planta teste (PIREs et al., 2001).

Através dosdadosapresentadospode-seconcluir queos extratos das diferentes espécies de bol do utilizadosinfluenciaram nagerminação ecausaramuma variação considerável no índice mitótico de cebola, apresentando assim efeito alelopático acelerando o desenvolvimento inicial das plântulas, além disto a cebola mostrou ser um biomonitor sensível a estes extratos.

\section{REFERÊNCIAS}

BeIguelman , B.Cursoprático debioestatística. 5.ed. Ribeirão Preto: Funpec, 2002. 274p.

Blanco, R.A. Boldo?Qual bol do?Disponível em: <http:/ / www.jardimdeflores.com.br/ ERVAS/ ervas.html >. A cesso em: 19 jun. 2005.

BRASIL. Ministério daAgriculturaereformaAgrária.R egras para análise de sementes. Brasília: MARA, 1992. 365p.

Carvalho,G.J.;Andrade,L.A.B.;Gomide,M.;FIgueiredo, P.A.M. Potencialidadesalelopáticas defolhasverdes + pontei ro decana-de-açúcar em diferentes concentrações de matéria seca, na germinação desementes de alface. Ciências, v.5, n.2, p.19-24, 1996.

CIAGRI.USP.Plantasmedicinais. Disponìvel em: <http:/ / ci66.ciagri.usp.br/ pm/ index.asp >. A cesso em: 16 jun. 2005
Chon, S.-U.;J ANG , H.-G.; KIM , D.-K.; KIM , Y.-M.;Boo, H-O; Kıм , Y.-J.Allelopathic potential in lettuce(Lactucasativa L.) plants. Scientia H orticulturae, v.106, p.309-317,2005.

Ferreira, A.G. \& Aquila, M.E.A. Alelopatia: Uma área emergente da ecofisiologia. R evista Brasileira deFisiologia V egetal, v.12, p.175-204, 2000. Suplemento.

Ferreira, A.G. \& BorghetTI,F. G erminação:dobásicoaoaplicado. Porto A legre: A rtmed, 2004. 323p.

Gattı, A.B.; Perez; S.C.J.G. De A.; Lı m A, M.I.S. A tividade alelopática de extratos aquosos de Aristolochia esperanzaeO. Kuntzenagerminação eno crescimento de L actuca sativa L. eR aphanus sativus L. A cta Botanica Brasilica, v.18, n.3, p.459-472, 2004.

Guerra, M.\&SouzA, M.J.Como observar cromossomos: um guia de técnica em citogenética vegetal, animal e humana. São Paulo: Funpec, 2002. 131p.

KAthiResan, R.M. Allelopathic potential of nativeplants against water hyacinth. Crop Protection, v.19, p.705708, 2000.

LAbouriau, L.G. A germinação de sementes. Washington: OEA, 1983. 174p.

Medeiros, A R.M.Alelopatia: importânciaesuasaplicações. H orti Sul, v.1, n.3, p.27-32, 1990.

N oldin , V.F.;M on ACHE, F.D.; Yunes, R.A.ComposiçãoquímicaeatividadebiológicadeCynarascolymusL.cultivada no Brasil. Química N ova, v.26, n.3, p.331-334, 2003.

Nunes,A.P.M.\&Araujo,A.C.Ausênciadegenotoxicidade de esteviosídeo em E. coli. In: SEMANA DE INICIAÇÃO CIENTÍFICA DA UNIVERSIDADE DO ESTADO DO RIO DE JANEIRO, 10, 2003, Rio de Janeiro. A nais.Rio de Janeiro, 2003. p.15.

PIREs, N.M.;SOUZA, I.R.P.;PRATES,H.T.;FARIA,T.C.L.;FILHO, I.A.P.; MAGA LHÃES, P.C. Efeito do extrato aquoso de leucena sobre o desenvolvimento, índice mitótico e atividadedaperoxidaseemplântulasdemilho.R evista Brasileira de Fisiologia V egetal, v.13, n.1, p.55-65, 2001.

Rodrigues, L.R.A.;R odrigues, T.J.D.; ReIs, R.A..A lelopatiaem plantas forrageiras. Jaboticabal: FCAVJ-UNESP/ FUNEP, 1992. 18p.

Recebi em 26/ 12/ 05

A ceito em 3/ 3/ 06 